\title{
Thermal Conductivity of Gases. II. Thermal Conduc- tivity of Carbon Dioxide Near the Critical Point ${ }^{1}$
}

\author{
Leslie A. Guildner
}

(April 13, 1962)

\begin{abstract}
The thermal conductivity of $\mathrm{CO}_{2}$ has been measured in a coaxial cylinder cell as a function of pressure over a range of temperatures from 3.66 to $75.26{ }^{\circ} \mathrm{C}$. Particular attention was given to the measurements from 1 to $9 \mathrm{deg} \mathrm{C}$ above the critical temperature at pressures closely spaced to include the critical density.

The thermal conductivity of $\mathrm{CO}_{2(\mathrm{~g})}$ near the critical point is very large compared to one atmosphere values around room temperature. At $1 \mathrm{deg} \mathrm{C}$ above the critical point the thermal conductivity reaches a maximum at the critical density. This maximum is greater than the maxima at higher temperatures. At $75.26^{\circ} \mathrm{C}, 44 \mathrm{deg} \mathrm{C}$ above the critical temperature, little unusual increase at the critical density was observed.

The rate of heat transport by convection in the critical region is also very large. This problem was studied carefully in order that the temperature differences used were restricted to the region of laminar flow, and that appropriate extrapolation procedures were used to find the rate of heat transfer by thermal conduction alone.

Also, at densities and temperatures away from the critical region, new thermal conductivity values were obtained.
\end{abstract}

\section{Introduction}

Despite a conveniently accessible critical temperature of about $31.045{ }^{\circ} \mathrm{C}$ and a moderate critical pressure of about $72.85 \mathrm{~atm}$, the transport phenomena in the critical region of carbon dioxide have received little attention. The viscosity of carbon dioxide has been measured by the oscillating disk method [1] ${ }^{2}$ and by capillary flow [2]. The thermal conductivity of carbon dioxide has been measured "in the critical region," [3] but in the range of density, $0.35<\rho<0.60$ $\mathrm{g} / \mathrm{cm}^{3}$, no measurements have been reported. Furthermore, other investigations have similarly failed to include the density range within $0.1 \mathrm{~g} / \mathrm{cm}^{3}$ of the critical [4] or have been at too high a temperature to demonstrate any characteristic behavior [5]. This paper describes a thermal conductivity investigation, emphasizing the region $32<t<40{ }^{\circ} \mathrm{C}$ and $0.4<\rho<0.55 \mathrm{~g} / \mathrm{cm}^{3}$ but including a wider range of both temperature and density.

\section{Experimental Description}

Thermal conductivities of $\mathrm{CO}_{2}$ were determined as functions of its pressure, average gas temperature and temperature difference. Following the design and considerations given in Paper I [6], a coaxial cylinder cell of 99.9 percent pure silver had a cell constant $C_{t}=C_{23} \varphi(t)$, where $C_{23}=1.207_{3} \times 10^{3} \mathrm{~cm}$ at $23{ }^{\circ} \mathrm{C}$ and the relative thermal expansion of silver is $\varphi(t)=\left[1+0.1862 \times 10^{-4}\left(t-23^{\circ}\right)+7.4 \times 10^{-9}\left(t-23^{\circ}\right)^{2}\right]$

\footnotetext{
1 This work was performed at the Massachusetts Institute of Technology and sponsored by Project SQUID, which is supported by the Office of Naval Research, Department of the Navy, under contract Nonr 1858(25) NR-098-038. Reproduction in full or in part is permitted for any use of the United States Government.

${ }^{2}$ Figures in brackets indicate the literature references at the end of this paper.
}

with $t$ in ${ }^{\circ} \mathrm{C}$. The cell and surrounding stainless steel container were maintained at a temperature constant to $\pm 0.001 \mathrm{deg} \mathrm{C}$ in an oil bath of the Beattie-Collins type [7], regulated by a proportionating thyratron circuit [8]. The temperature was obtained on the international scale using a platinum resistance thermometer and Mueller bridge, both carefully calibrated.

In order to make them stable, the Chromel-P Alumel thermocouples used to measure the temperature difference were annealed in an atmosphere of $\mathrm{CO}_{2}$ for $205 \mathrm{hr}$ at $500{ }^{\circ} \mathrm{C}$. As a further protection from parasitic emfs from strain, non-uniformity of composition and non-uniform temperature at the junction with copper outside the system, the thermocouple wires were welded to gold and the junctions tempered-brought into good thermal contact-at a "lava block" below the top of the constant temperature bath. (See fig. 1.) The leads of one reference junction, maintained at $0{ }^{\circ} \mathrm{C}$ in an ice bath, were brought into the cell-container. Gold leads were welded to the reference thermocouple leads also, and the gold-thermocouple junctions were tempered in the same tempering block as the other gold-thermocouple junctions. After emerging from the cell, the contact between each gold lead and its copper lead was made in thermal contact with a large copper block which was well insulated thermally. The leads of each thermocouple junction, by extension with a gold and then a copper intermediary, were wired into a set of switches, in such a way that all pair combinations were possible.

As part of the lead tempering, it was necessary to provide a portion of the gold thermocouple lead wires with a constant temperature environment. The use of some device such as the "heater" shown in figure 1 was necessary, particularly if the gas was at high enough pressure to be liquefied in the gas lead 


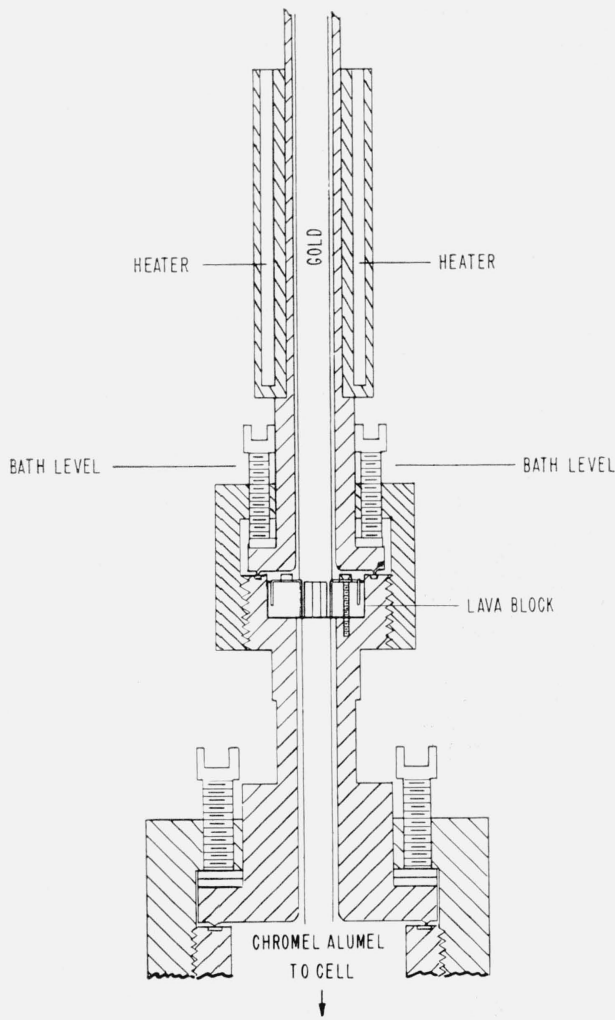

FiguRE 1. Heater and lava block tempering station for thermocouple leads.

above the cell. This heater was controlled so as to produce a constant temperature excess $\Delta t$ above the bath temperature. With $\mathrm{CO}_{2}$ at $75^{\circ} \mathrm{C}$ bath temperature it was found necessary to use different $\Delta t$ values, depending upon the pressure, but it proved true that the minimum value which made the thermocouple voltages steady gave constant calibration results.

Electromotive forces of the thermocouples were determined by potentiometric measurement, on an instrument with dials reading directly to single microvolts. The range was extended to hundredths of microvolts by galvanometer deflections. The sensitivity for the temperature difference readings was $31.4 \mathrm{~mm} / \mu \mathrm{v}$ with a reading error of $0.1 \mathrm{~mm}$. The potentiometer was calibrated both absolutely and for proportionality in 1947, fourteen years after its construction, and was recalibrated for proportionality during the course of the measurements. The power was also determined by potentiometric measurements with voltage divider networks, where all components had been carefully calibrated.

Carbon dioxide, available as liquid in tanks at 99.5 percent $^{3}$ purity, was first passed, in the gaseous phase, through a magnesium perchlorate drying tube and then frozen at liquid nitrogen temperatures. After vacuum pumping for several hours, the residual pressure was reduced to 0.3 percent of its original value, then indicating residual contamination of the

${ }^{3}$ Pure Carbonic Co. states the impurities of the gas used as $0.342 \% \mathrm{~N}_{2}, 0.086 \%$ $\mathrm{O}_{2}$, and $0.072 \% \mathrm{H}_{2} \mathrm{O}$.
$\mathrm{O}_{2}$ and $\mathrm{N}_{2}$ impurity of $<0.001$ percent. The $\mathrm{CO}_{2}$ pressures were measured on a dead-weight piston gage, calibrated against the vapor pressure of $\mathrm{CO}_{2}$ at $0{ }^{\circ} \mathrm{C}[9]$, with calibrated weights.

Pressures were controlled by a special regulator system to about 1 part in 100,000 .

\section{Measurements}

To permit the specification of density near the critical density as accurately as possible, the pressures for conductivity measurements were selected at average gas temperatures of $32.054,34.721,40.089$, and $75.260^{\circ} \mathrm{C}$, because these are the temperatures of the $p V T$ isotherms of Michels and Michels [10], and Michels, Blaisse, and Michels [11]. From these $p V T$ data and the determinations of Wentorf [12], the value of $\rho=0.474 \mathrm{~g} / \mathrm{cm}^{3}$ was assumed for the critical density. At lower pressures and also in the liquid state, the values of density were derived from equations of state. Other conductivity measurements covering a large density range were made at about $3.7,26,31$, and $36{ }^{\circ} \mathrm{C}$.

To permit extrapolation of the apparent conductivity to that at zero temperature difference, two sets of triplicate measurements of the top and middle emitter-receiver difference thermocouples were made at three different $\Delta t$ 's in the ratio of 1: 2: 4 with constant average gas temperature. When conditions permitted, a maximum temperature difference of about 5 deg $\mathrm{C}$ was considered optimal. In some cases near the critical point, however, the danger of turbulent flow made it desirable that the maximum temperature difference be only $0.025 \mathrm{deg} \mathrm{C}$.

When experimental conditions made it uncertain whether turbulent convection existed, exploratory measurements were made to locate a possible transition from laminar to turbulent flow. If it was found, the determinations for extrapolations were made for temperature differences less than that which produced surbulence.

The blank was measured at two temperatures at the beginning of the investigation. The stability and reproducibility of the blank was shown by repeating the measurements toward the end of the work.

With no power input in the cell, there should be no difference in temperature between the emitter and receiver, but appreciable difference thermocouple emf's were still found to exist. In general, within the range of 0 to $75^{\circ} \mathrm{C}$, these "residual" or "parasitic" voltages were less than $\pm 1 \mu \mathrm{v}$ and they were fairly stable. They might have been due to heat flows to the cell, or to strain and variation of composition of leads in the temperature gradient between the cell and room temperature. In any case the parasitic emf's amounted to a "zero calibration" and they were deducted from the measurements when the emitter was heated. The importance of this procedure was emphasized for measurements near the critical point, where some of the net emf's for the temperature difference were less than the parasitic emf. 


\section{Results}

\subsection{Treatment of Data}

The principal data obtained for a determination of the apparent conductivity were

(1) The emf across the voltage divider of the emitter heater, $V_{\text {em }}$.

(2) The emf across the voltage divider of the standard resistor, $V_{\text {std. }}$.

(3) The emf of the emitter-receiver difference thermocouples, $\Delta V_{\Delta t}$.

(4) The emf of the emitter-heat guard difference thermocouple.

(5) The emf of the receiver-ice thermocouple.

(6) The weights for the deadweight gage measurement of pressure.

(7) The platinum thermometer resistance for the bath temperature.

Items (5) and (6), together with calibrations, allowed a specification of the pressure and temperature of the gas. Items (4) and (7) permitted maintenance of required experimental conditions. The apparent thermal conductivity obtained from a set of measurements is defined as $K_{\mathrm{app}}=\frac{\dot{q}}{C_{t} \Delta t}$. Now $\dot{q}$, the power, is the product of the emf's of the emitter and standard resistor times a number representing the calibrated factors for the voltage dividers, divided by the resistance of the standard resistor. The temperature difference, $\Delta t$, is obtained from the emf's of the emitter-receiver difference thermocouples, $\Delta V_{\Delta t}$, divided by the calibrated value of $d E / d t$ for Chromel-P Alumel at the average temperature. Thus

$$
K_{\mathrm{app}}=\frac{\dot{q}}{C_{t} \Delta t}=\left(\frac{V_{\mathrm{em}} V_{\mathrm{std}}}{\Delta V_{\Delta t}}\right) D_{23}\left(\frac{d E}{d t} / \phi(t)\right) .
$$

This requires

$$
\begin{aligned}
D_{23}=\frac{0.23885 X}{C_{23} R_{\text {std }}}= & 1.321_{96} \\
& \quad \times 10^{-11} \text { I. T. cal } \mathrm{cm}^{-1} \mathrm{sec}^{-1}(\mu \mathrm{v})^{-2}
\end{aligned}
$$

where $X$ is the appropriate factor for the voltage dividers. The results in this paper are expressed with heat units in I.T. calories, based on the conversion 1 absolute joule $=0.23885$ I.T. calories. At constant average gas temperature, $d E / d t$ and $\varphi(t)$ are constant. The only variables of eq (1) for an isotherm, therefore, are the emf measurements. The computations are greatly reduced by processing the emf product to obtain the value extrapolated to zero difference thermocouple emf. If we put

$$
\Psi=\frac{V_{\mathrm{em}} V_{\mathrm{std}}}{\Delta V_{\Delta t}},
$$

the coordinates of the extrapolations are $\Psi$ versus $\Delta V_{\Delta t}$. Corrections were made to $\Psi$ for small deviations from the steady state. The heat flow between emitter and heat guard, if the temperature difference was not zero, was determined as a function of the conductivity and corrections applied. A linear change in the rate that power was supplied to the emitter required a correction to represent a steady state measurement. It was obtained from $K_{\text {corr }}=$ $K_{\text {app }}+\frac{2 \alpha C_{p}}{C_{t}}$, where $\alpha$ is the relative rate of change of the heating current, $C_{p}$ is the heat capacity of the emitter and $C_{t}$ is the cell constant. Usually these corrections were insignificant and for no measurements did the total correction exceed 0.2 percent. When $\Psi$ is extrapolated to zero $\Delta V_{\Delta t}$ to give $\Psi_{0}$, the corresponding $K_{\text {app }}$ is $\left(K_{\text {app }}\right)_{0}$. Corrections for the assymetric temperature distribution, $f\left(K_{\text {app }}\right)_{0}$, the perturbation of heat flow by the pins, $-7 \times 10^{-4}$ $\left(K_{\text {app }}\right)_{0}$, and the temperature gradient in the emitter and receiver, $10.70\left(K_{\text {app }}\right)_{0}^{2}$, were made as $\Sigma \delta K=$ $\left(f-7 \times 10^{-4}\right) \quad\left(K_{\text {app }}\right)_{0}+10.70\left(K_{\text {app }}\right)_{0}^{2}$. Finally, the blank was deducted to arrive at the conductivity of the gas, $K=\left(K_{\mathrm{app}}\right)_{0}-$ blank $+\Sigma \delta K$.

\subsection{Calibrations of a Reference Thermocouple, Extrapolations of $\Psi$ Versus $\Delta V_{\Delta t}$ and Calculation of $K$}

The reference thermocouple was installed so it could be calibrated against a platinum resistance thermometer in the bath. Values of the emf versus $t$ were obtained by repeated measurements at $5 \mathrm{deg}$ temperature intervals. The curve of $d E / d t$ versus $t$ for Chromel-P Alumel (fig. 2) was obtained by numerical differentiation. Small adjustments, up to one part in 2,000, were made and compensated for

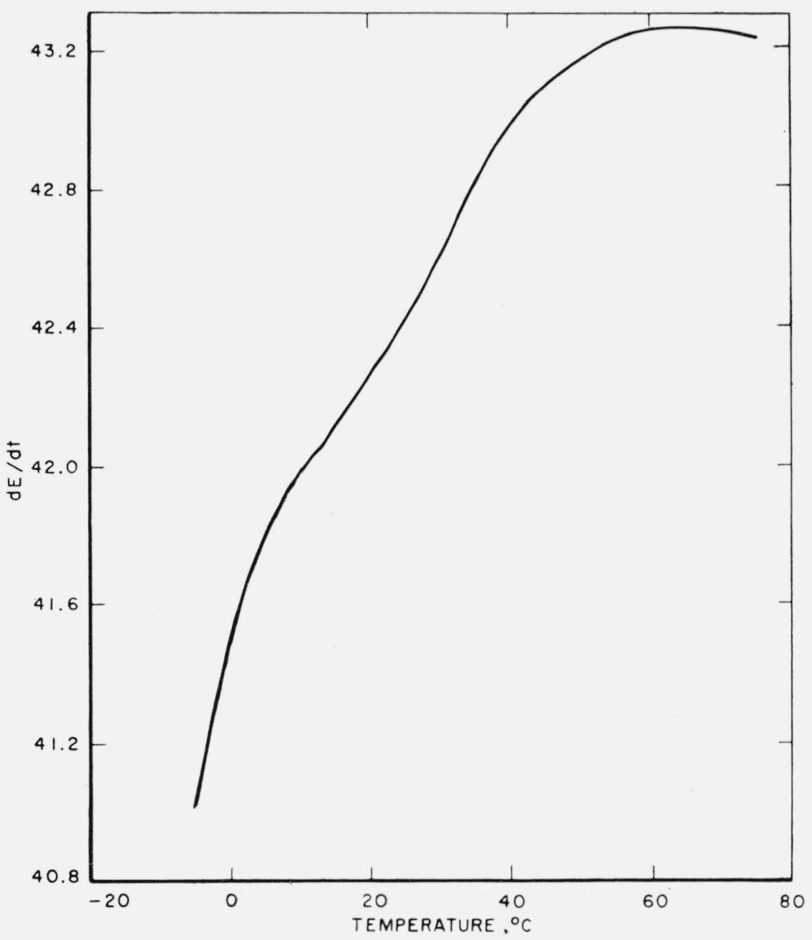

Figure 2. $d E / d t(\mu \mathrm{v} / \operatorname{deg} C)$ for Chromel-P Alumel thermocouples from 0 to $75^{\circ} \mathrm{C}$. 
in the adjoining values. The integrated values for $E$ checked the calibration values of $745.3,1691.15$, and $3202.6 \mu \mathrm{v}$ within $0.1 \mu \mathrm{v}$ at 18,40 , and $75{ }^{\circ} \mathrm{C}$, and within $0.2 \mu \mathrm{v}$ of $2208.2 \mu \mathrm{v}$ at $52{ }^{\circ} \mathrm{C}$.

Sample data and the calculated $\Psi$ are shown in table 1 for one point on curve 5 , figure 3 , for $\Delta V_{\Delta t}=$ $38 \mu \mathrm{v}$. Residuals have been deducted. They were about $+0.045 \mu \mathrm{v}$ for upper em-rec, and $-0.250 \mu \mathrm{v}$ for lower em-rec difference thermocouples.

Extrapolations exhibiting the change in slope typical of the increase of heat transport by turbulent convection are shown in lines $1,2,3,4$, and 5 of figure 3 . $X$ on the lines $2,3,4$, and 5 indicates the

TABLE 1. Potentiometer measurements for thermal conductivity of $\mathrm{CO}_{2(\mathrm{~g})}$

$t=75.26{ }^{\circ} \mathrm{C}, p=178.2 \mathrm{~atm}$

\begin{tabular}{|c|c|c|c|c|c|c|c|c|}
\hline \multirow[t]{2}{*}{ Time } & \multicolumn{2}{|c|}{$\Delta V_{\Delta t}$ em-rec } & \multirow[t]{2}{*}{$\begin{array}{c}\mathrm{Ave} \\
\Delta V_{\Delta t}\end{array}$} & \multirow[t]{2}{*}{$V_{\text {std }}$} & \multirow[t]{2}{*}{$\boldsymbol{V}_{\mathrm{em}}^{\prime}$} & \multirow{2}{*}{$\begin{array}{c}10^{-5} \\
\Psi\end{array}$} & \multirow{2}{*}{$\begin{array}{l}10^{-5} \\
\Psi \text { Ave }\end{array}$} & \multirow{2}{*}{$\begin{array}{c}\left(\Delta V_{\Delta t}\right) \\
\text { Ave }\end{array}$} \\
\hline & upper & lower & & & & & & \\
\hline $\begin{array}{l}2.00 \mathrm{P} \\
2.30 \mathrm{P} \\
2.55 \mathrm{P}\end{array}$ & $\begin{array}{l}38.261 \\
38.284 \\
38.203\end{array}$ & $\begin{array}{l}38.224 \\
38.209 \\
38.174\end{array}$ & $\begin{array}{l}38.244 \\
38.247 \\
38.189\end{array}$ & $\begin{array}{l}3008.27 \\
3007.61 \\
3006.68\end{array}$ & $\begin{array}{l}3736.46 \\
3735.68 \\
3734.47\end{array}$ & $\begin{array}{l}2.939 \\
2.938 \\
2.940\end{array}$ & 2. 939 & 38.23 \\
\hline $\begin{array}{l}4.30 \mathrm{P} \\
4.45 \mathrm{P} \\
5.00 \mathrm{P}\end{array}$ & $\begin{array}{l}38.198 \\
38.147 \\
38.168\end{array}$ & $\begin{array}{l}38.137 \\
38.100 \\
38.144\end{array}$ & $\begin{array}{l}38.168 \\
38.124 \\
38.156\end{array}$ & $\begin{array}{l}3005.01 \\
\text { 3003. } 22 \\
3001.83\end{array}$ & $\begin{array}{l}3732.08 \\
3730.20 \\
3728.36\end{array}$ & $\begin{array}{l}2.938 \\
\text { 2. } 939 \\
2.933\end{array}$ & 2. 937 & 38.15 \\
\hline
\end{tabular}

The data are typical for $\Delta V_{\Delta t} \geq 25 \mu \mathrm{V}$ where the average deviation was $\pm 0.1 \%$.

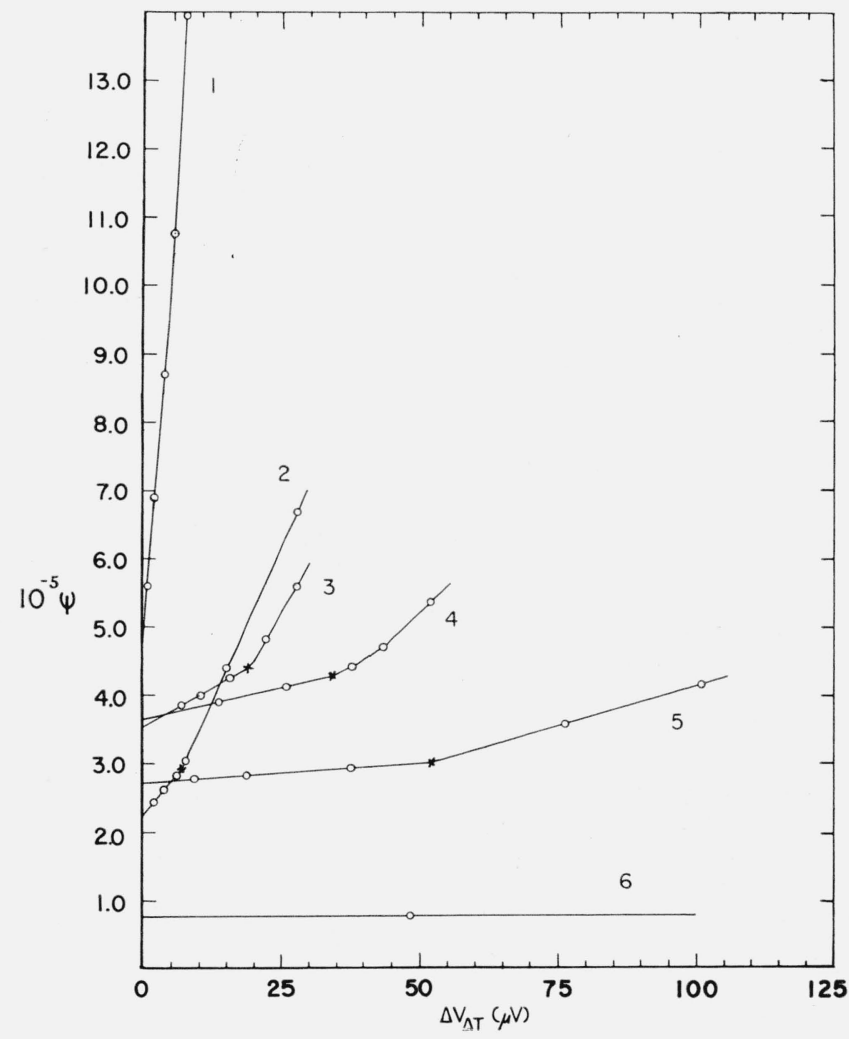

FiguRE 3. Extrapolation curves showing change to turbulent convection. (1) $t=34.721{ }^{\circ} \mathrm{C}, p=79.13 \mathrm{~atm}$; (2) $t=32.054{ }^{\circ} \mathrm{C}, p=72.51$ atm; (3) $t=25.99{ }^{\circ} \mathrm{C}$,
$p=68.71 \mathrm{~atm}$; (4) $t=25.99{ }^{\circ} \mathrm{C}, p=75.85 \mathrm{~atm}$; (5) $t=75.26{ }^{\circ} \mathrm{C}, p=178.2 \mathrm{~atm}$; (6) $t=$ $p=68.71$
$41.22^{\circ} \mathrm{C}, p=2.31$ atm. calculated value of $\Delta V_{\Delta t}$ for the Reynolds number $R \mathrm{e}=25$. A part of a typical low-pressure extrapolation, line 6 , is shown for comparison.

A summary of all the results is presented in table 2 .

Column 3 gives the highest emf of the difference thermocouples used in the extrapolations. Column 4 gives the emf of the difference thermocouples for the transition to turbulence. $D=D_{23} / \varphi(t)$.

The isotherms of $K$ versus $\rho$ in the region of critical density are presented graphically in figure 4 . The detail of the isotherms at $3.662,26.00,30.90,36.24$, and $41.22{ }^{\circ} \mathrm{C}$ for $\rho<0.20 \mathrm{~g} / \mathrm{cm}^{3}$ are shown in figure 5 .

TABLE 2. Summary of results

\begin{tabular}{|c|c|c|c|c|c|c|c|c|}
\hline \multirow[t]{2}{*}{$\mathrm{P}$ (atm) } & \multirow{2}{*}{$\begin{array}{c}\rho \\
\left(\mathrm{g} / \mathrm{cm}^{3}\right)\end{array}$} & \multirow{2}{*}{$\begin{array}{c}\text { Max } \Delta t \\
\text { Extrap } \\
(\mu \mathrm{v})\end{array}$} & \multirow{2}{*}{$\underset{(\mu \mathrm{V})}{\operatorname{Turb} \Delta t}$} & \multirow{2}{*}{$\begin{array}{c}10^{-5} \Psi_{0} \\
(\mu \mathrm{V})\end{array}$} & $\left(K_{\mathrm{app}}\right)_{0}$ & $\Sigma \delta K$ & $K$ & \multirow{2}{*}{$\begin{array}{c}\text { Probable } \\
\text { error } \\
(\%)\end{array}$} \\
\hline & & & & & \multicolumn{3}{|c|}{$10^{5} \mathrm{cal} \mathrm{em}^{-1} \mathrm{sec}^{-1} \operatorname{deg} \mathrm{C}^{-1}$} & \\
\hline
\end{tabular}

$3.662{ }^{\circ} \mathrm{C} ; D=1.3224 \times 10^{-11} ; d E / d t=41.76 \mu \mathrm{v} /$ deg $\mathrm{C} ; 10^{5}$ blank $=0.140$

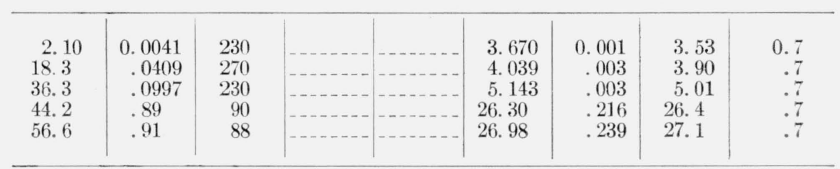

$26.00^{\circ} \mathrm{C} ; D=1.3219 \times 10^{-11} ; d E / d t=42.48 \mu \mathrm{v} / \mathrm{deg} \mathrm{C} ; 10^{5} \mathrm{blank}=0.155$

\begin{tabular}{l|r|r|r|r|r|r|r|r}
\hline 2.18 & 0.0036 & 230 & & & & & & \\
31.16 & .0685 & 195 & -5.044 & 0.003 & 3.89 & 0.5 \\
56.9 & .1696 & 64 & 70 & -5.54 & 6.819 & .003 & 4.54 & .5 \\
68.7 & .73 & 16 & 18 & 3.545 & 19.91 & .122 & 6.67 & .6 \\
75.9 & .76 & 26 & 35 & 3.641 & 20.45 & .132 & 20.4 & 0.0 \\
\hline
\end{tabular}

$30.90^{\circ} \mathrm{C} ; D=1.3218 \times 10^{-11} ; d E / d t=42.65 \mu \mathrm{v} / \mathrm{deg} \mathrm{C} ; 10^{5} \mathrm{blank}=0.160$

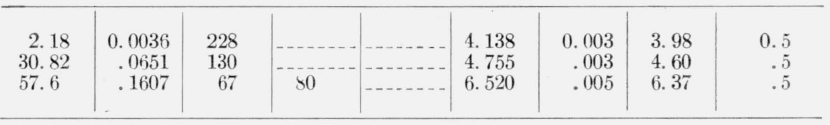

$31.31{ }^{\circ} \mathrm{C} ; D=1.3218 \times 10^{-11} ; d E / d t=42.66 \mu \mathrm{v} / \mathrm{deg} \mathrm{C} ; 10^{5} \mathrm{blank}=0.160$

\begin{tabular}{l|l|l|l|l|l|l|l|l}
\hline 77.70 & 0.652 & 13 & 16 & 3.495 & 19.71 & 0.120 & 19.7 & 1 \\
\hline
\end{tabular}

$32.05{ }^{\circ} \mathrm{C} ; D=1.3217 \times 10^{-11} ; d E / d t=42.68 \mu \mathrm{v} / \mathrm{deg} \mathrm{C} ; 10^{5} \mathrm{blank}=0.161$

\begin{tabular}{|c|c|c|c|c|c|c|c|c|}
\hline 72.51 & 0.300 & 6 & 7 & 2. 295 & 12.95 & 0.051 & 12.8 & 1. 5 \\
\hline 74. 29 & .398 & 1 & & 5. 475 & 30.88 & .303 & 31 & 6 \\
\hline 74.49 & .4482 & 1 & & 10.03 & 56. 58 & 1. 001 & 57 & 7 \\
\hline 74.56 & .4758 & 2.3 & & 12.16 & 68.59 & 1. 439 & 70 & 8 \\
\hline 74.62 & .498 & 1.1 & & 8. 720 & 49.19 & 0.812 & 50 & 7 \\
\hline 74. 99 & .553 & 1. 7 & 2.1 & 4. 923 & 27.77 & .245 & 28 & 6 \\
\hline 75.90 & .600 & 2. 6 & 3.4 & 3.800 & 21.44 & .144 & 21.4 & 4 \\
\hline 79.67 & .650 & 7 & & 3.476 & 19.61 & .120 & 19.6 & 2 \\
\hline
\end{tabular}

$34.72_{1}{ }^{\circ} \mathrm{C} ; D=1.3217 \times 10^{-11} ; d E / d t \times 42.79 \mu \mathrm{v} / \mathrm{deg} \mathrm{C} ; 10^{5} \mathrm{blank}=0.164$

\begin{tabular}{l|c|c|c|c|c|c|c|c}
\hline 78.18 & 0.400 & 4 & 5.3 & 3.630 & 20.53 & 0.132 & 20.5 & 3 \\
79.13 & .474 & 4 & 4.5 & 4.570 & 25.85 & .213 & 25.9 & 3 \\
80.46 & .550 & 7 &.---1 & 3.545 & 20.05 & .123 & 20.0 & 2 \\
\hline
\end{tabular}

$36.24^{\circ} \mathrm{C} ; D=1.3216 \times 10^{-11} ; d E / d t=42.81 \mu \mathrm{v} / \mathrm{deg} \mathrm{C} ; 10^{5} \mathrm{blank}=0.166$

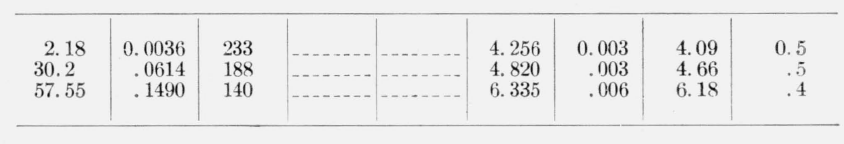


TABLE 2. Summary of results-Continued

\begin{tabular}{|c|c|c|c|c|c|c|c|c|}
\hline \multirow[t]{2}{*}{$\mathrm{P}$ (atm) } & \multirow{2}{*}{$\begin{array}{c}\rho \\
\left(\mathrm{g} / \mathrm{em}^{3}\right)\end{array}$} & \multirow{2}{*}{$\begin{array}{c}\text { Max } \Delta t \\
\text { Extrap } \\
(\mu \mathrm{v})\end{array}$} & \multirow{2}{*}{$\underset{(\mu \mathrm{v})}{\operatorname{Turb}} \Delta t$} & \multirow{2}{*}{$\begin{array}{c}10^{-5} \psi_{0} \\
(\mu \mathrm{V})\end{array}$} & $\left(K_{\mathrm{apD}}\right)_{0}$ & $\Sigma \delta K$ & $K$ & \multirow{2}{*}{$\begin{array}{c}\text { Probable } \\
\text { error } \\
(\%)\end{array}$} \\
\hline & & & & & \multicolumn{3}{|c|}{ 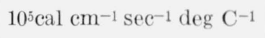 } & \\
\hline
\end{tabular}

$40.08{ }^{\circ} \mathrm{C} ; D=1.3215 \times 10^{-11} ; d E / d t=42.99 \mu \mathrm{v} / \mathrm{deg} \mathrm{C} ; 10^{5} \mathrm{blank}=0.170$

\begin{tabular}{l|r|l|l|l|l|l|l|l}
\hline 85.81 & 0.400 & 6 & & & & & & \\
88.91 & .474 & 2 & -107 & 15.38 & 0.072 & 15.3 & 2 \\
91.85 & .550 & 9 & 10.5 & 3.941 & 16.71 & .087 & 16.6 & 4 \\
& & & & & 17.85 & .099 & 17.8 & 1.5
\end{tabular}

$40.107{ }^{\circ} \mathrm{C} ; D=1.3215 \times 10^{-11} ; d E / d t=42.99 \mu \mathrm{v} / \mathrm{deg} \mathrm{C} ; 10^{5} \mathrm{blank}=0.170$

\begin{tabular}{l|r|l|l|l|l|l|l|r}
\hline 124.9 & 0.737 & 32 & 40 & 3.493 & 19.84 & 0.122 & 19.8 & 0.5 \\
195.2 & .840 & 95 & $-\cdots-1$ & 4.089 & 23.23 & 0.170 & 23.23 & .3
\end{tabular}

$41.22^{\circ} \mathrm{C} ; D=1.3215 \times 10^{-11} ; d E / d t=42.99 \mu \mathrm{v} / \operatorname{deg} \mathrm{C} ; 10^{5}$ blank $=0.171$

\begin{tabular}{r|r|r|r|r|r|r|r}
2.31 & 0.0040 & 200 & & & & & \\
57.69 & .1412 & 140 & $-\ldots-1.332$ & 0.003 & 4.16 & 0.5 \\
& & & & & .006 & 6.00 & .4 \\
\hline
\end{tabular}

$73.79^{\circ} \mathrm{C} ; D=1.3207 \times 10^{-11} ; d E / d t=43.04 \mu \mathrm{v} / \mathrm{deg} \mathrm{C} ; 10^{5} \mathrm{blank}=0.206$

\begin{tabular}{l|l|l|l|l|l|l|l}
2.31 & 0.0036 & 200 & $\ldots \ldots \ldots$ & 4.969 & 0.003 & 4.77 & 0.5 \\
\hline
\end{tabular}

$75.26^{\circ} \mathrm{C} ; D=1.3207 \times 10^{-11} ; d E / d t=43.22 \mu \mathrm{v} / \mathrm{deg} \mathrm{C} ; 10^{5} \mathrm{blank}=0.207$

\begin{tabular}{l|r|l|l|l|l|l|l|r}
\hline 150.7 & 0.474 & 40 & 42 & 2.306 & 13.16 & 0.052 & 13.01 & 0.6 \\
178.2 & .575 & 38 & 50 & 2.739 & 15.63 & .075 & 15.50 & .5 \\
300.0 & .770 & 30 & 50 & 3.659 & 20.89 & .137 & 20.8 & .5 \\
\hline
\end{tabular}

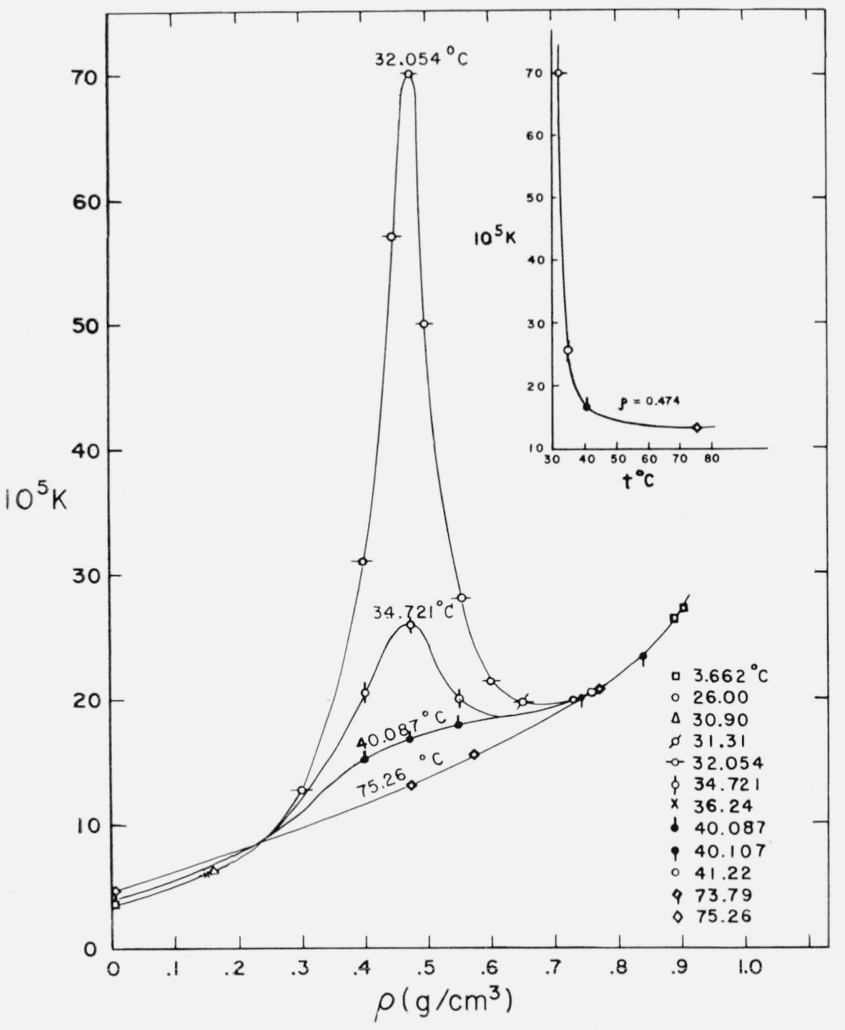

Figure 4. Thermal conductivity of $\mathrm{CO}_{2}$ in the region of the critical point.

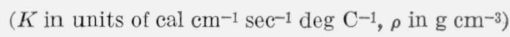

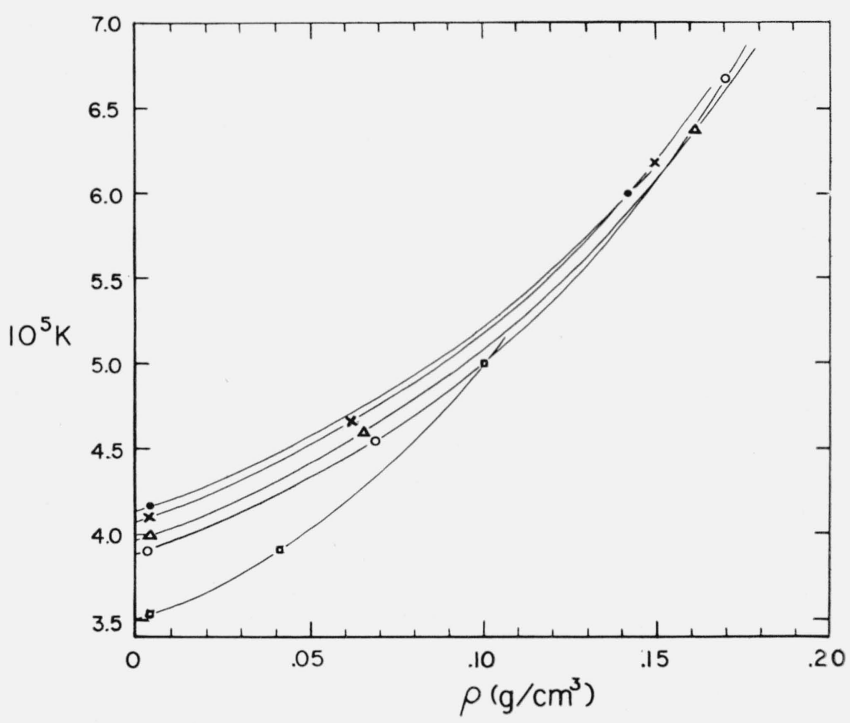

Figure 5. Thermal conductivity of $\mathrm{CO}_{2}(g)$ at low densities from 3.66 to $41.22^{\circ} \mathrm{C}$.

$K$ in units of eal $\mathrm{cm}^{-1} \mathrm{sec}^{-1} \operatorname{deg} \mathrm{C}^{-1}, \rho$ in $\mathrm{g} \mathrm{cm}^{-3}$ ) Same key as figure 4.

\section{A Study of Convection for the 32.054 ${ }^{\circ} \mathrm{C}$ Isotherm}

The maximum temperature difference, which can exist before the onset of turbulence, becomes smaller as the crtical conditions are approached. Since there is a loss of precision at very small temperature differences, it may not be possible to determine by experiment whether extrapolations of measurements close to the critical point are entirely in the laminar range. Thus, the extrapolations for $32.054{ }^{\circ} \mathrm{C}$ a verage gas temperature at $0.398,0.448,0.4758$, and $0.498 \mathrm{~g} / \mathrm{cm}^{3}$ density, shown in figure 6 , might include one or more points involving turbulent heat transport.

The temperature difference for the transition to turbulent flow can be evaluated by calculating that value of $\Delta \mathrm{t}$ for which the Reynolds number equals 25 . From paper I, Re $=-\frac{g(\Delta r)^{3}}{384}\left(\frac{\partial \rho}{\partial t}\right)_{p} \frac{\rho \Delta t}{\eta^{2}}$. The evaluation of some of these quantities near the critical point is tenuous, so the results of calculations are only approximate. For instance, without a careful study leading to a reliable equation of state, $\left(\frac{\partial \rho}{\partial t}\right)_{p}$ must have an uncertainty of 5 to 10 percent. It was found that $\left(\frac{\partial p}{\partial t}\right)_{\rho}$ is very nearly constant from 31.185 to $34.721{ }^{\circ} \mathrm{C}$ for a given $\rho$, hence $\left(\frac{\partial \rho}{\partial t}\right)_{p}$ was evaluated from $\left(\frac{\partial \rho}{\partial t}\right)_{p}=-\left(\frac{\partial \rho}{\partial p}\right)_{t}\left(\frac{\partial p}{\partial t}\right)_{\rho}$. The experi mental values of the viscosity of $\mathrm{CO}_{2}$ vary even more. At $31.10^{\circ} \mathrm{C}$ and $0.504 \mathrm{~g} / \mathrm{cm}^{3}$ Michels, Botzen, and Schuurman reported $\eta$ to be $76 \times 10^{-5}$ poise. On 


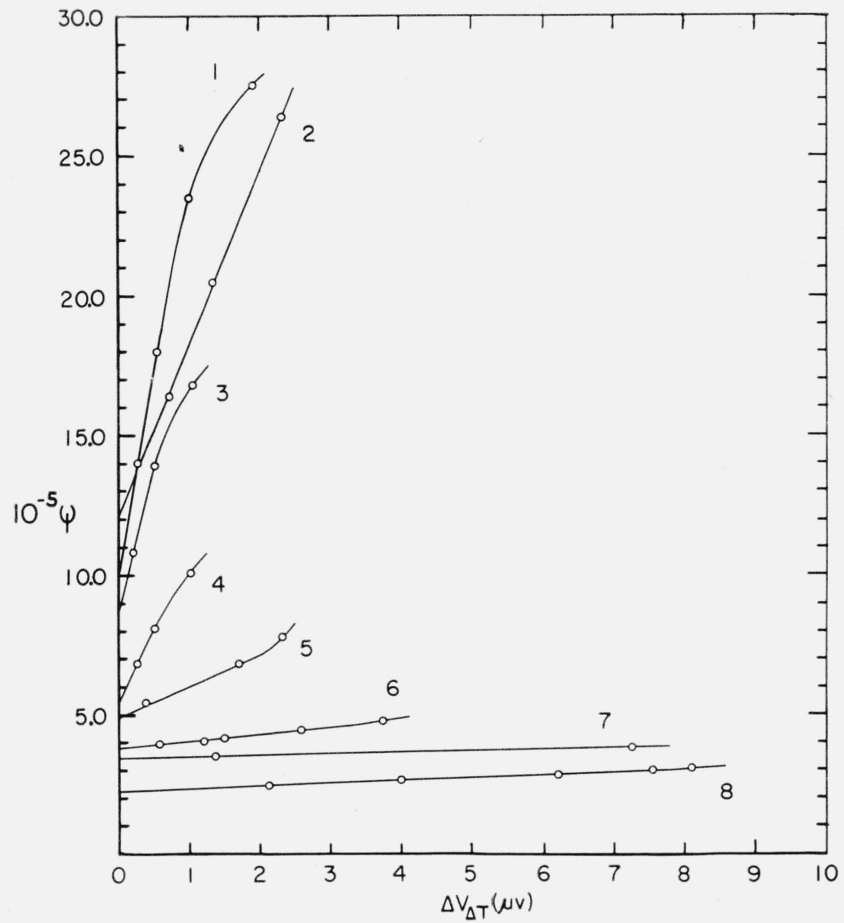

IGURE 6. Extrapolation curves near the critical density for the $32.054^{\circ} \mathrm{C}$ isotherm.

(1) $\rho=0.4482 \mathrm{~g} \mathrm{~cm}^{-3}$; (2) $\rho=0.4758 \mathrm{~g} \mathrm{~cm}^{-3}$; (3) $\rho=0.498 \mathrm{~g} \mathrm{~cm}^{-3}$; (4) $\rho=0.398 \mathrm{~g} \mathrm{~cm}^{-3}$; (5) $\rho=0.553 \mathrm{~g} \mathrm{~cm}^{-3} ;(6) \rho=0.600 \mathrm{~g} \mathrm{~cm}^{-3}$; (7) $\rho=0.650 \mathrm{~g} \mathrm{~cm}^{-3} ;(8) \rho=0.300 \mathrm{~g} \mathrm{~cm}^{-3}$.

the other hand, at $31.14{ }^{\circ} \mathrm{C}$ and $0.502 \mathrm{~g} / \mathrm{cm}^{3}$, Naldrett and Maass reported $\eta$ to be $37.91 \times 10^{-5}$ poise, or almost exactly one-half as much. In table 3 one set of values of $\Delta t$ for transition to turbulence is given for the viscosities reported by Michels, Botzen, and Schuurman, and another set for the viscosities reported by Naldrett and Maass.

Table 3 shows at least two points on every extrapolation line except for $\rho=0.4758$ are within the limits of temperature difference for laminar convection. For values of viscosity reported by Naldrett and Maass, the calculations show that turbulence can be expected only when $\Delta t$ is greater than the maximum used in the extrapolations for $\rho=0.300, \rho=0.398$, and $\rho=0.553$. For the largest temperature difference, the heat transfer would include turbulence at $\rho=0.448$ and $\rho=0.498$ but not for the two smaller temperature differences. However, the rate of heat transfer at the highest temperature difference at $\rho=0.4482$ or $\rho=0.498$ is too low even to be linear with other points. At $\rho=0.4758$, (approximately the critical density), according to the calculation only the lowest temperature difference is within the limits of laminar flow. This is remarkable if true, since the slope of the extrapolation at $\rho=0.4758$ is less than that at $\rho=0.4482$ or $\rho=0.498$, hardly a manifestation of turbulence.

The values of viscosity reported by Naldrett and Maass show no unusual increase at the critical density. The only significant uncertainty, then, in the correct values of the viscosity is between those values and higher values. If the higher values of viscosity reported by Michels, Botzen, and Schuurman are used, the calculated temperature difference for transition to turbulence is greater than the temperature differences used in the extrapolations at all densities except the critical density.

The usefulness of these considerations is that one must conclude, even from a very conservative evaluation, that the important part of the extrapolations are based on measurements made under conditions of laminar flow.

\section{Discussion}

At low pressures, the measurements were made so that the temperature difference indicated by the thermocouple $\mathrm{emf} \geq 25 \mu \mathrm{v}$. This allows $\Psi_{0}$ to be determined with an uncertainty of about \pm 0.1 percent, as a combination of uncertainty in the individual values and the uncertainty introduced by the extrapolation. The value of $D$ is uncertain by \pm 0.1 percent because of uncertainty in mechanical measurements for the cell constant. The $d E / d t$ for the Chromel-P Alumel thermocouples is considered to be uncertain by \pm 0.1 percent also.

The blank was difficult to determine, and initial determinations, shortly after beginning the conductivity measurements, varied by \pm 5 percent.

Determinations made at the conclusion of measurements agreed with the initial values within that variation. The uncertainty of the blank is insignificant for values of $10^{5} \mathrm{~K} \geq 10 \mathrm{cal} \mathrm{cm}^{-1} \mathrm{sec}^{-1} \mathrm{deg} \mathrm{C}^{-1}$ relative to the other errors, but at $3.7^{\circ} \mathrm{C}$ it contributes \pm 0.2 percent for $10^{5} K=3.5$.

TABLE 3. Temperature difference for transition to turbulent flow at $32.054^{\circ} \mathrm{C}$ near the critical density

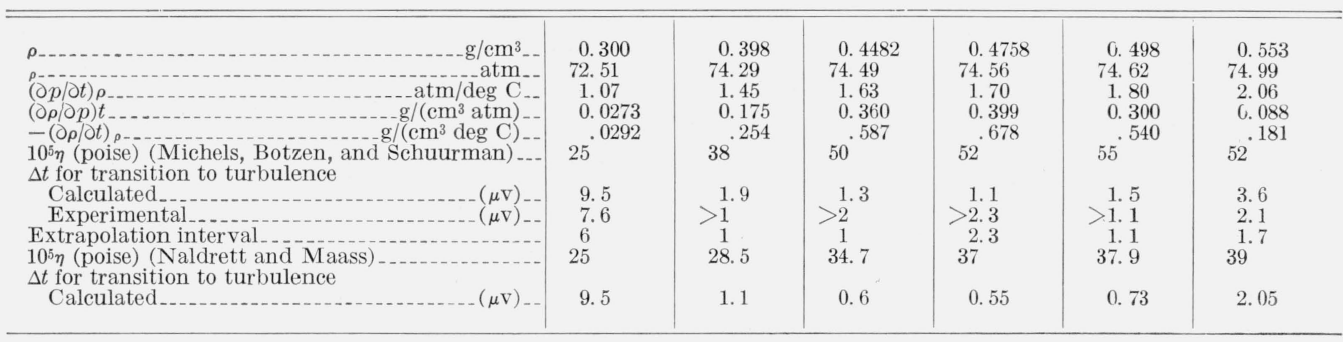


The $3.66{ }^{\circ} \mathrm{C}$ isotherm was the first to be measured. It is considered that the reliability of the data improved with experience, hence a larger estimated uncertainty for this isotherm is given in table 2 than for other measurements under comparable conditions.

The uncertainty of the values near the critical point is considered to be primarily due to lack of reproducibility of the small emf's of the difference thermocouples. Measurements at $0.25 \mu \mathrm{v}$ were precise within \pm 5 percent (i.e., $\pm 0.0003 \mathrm{deg}$ C). At least 12 emf measurements are included in the value of a $0.25 \mu \mathrm{v}$ point.

The curvature of the extrapolations for $\rho=0.45$. 0.50 and $0.55 \mathrm{~g} / \mathrm{cm}^{3}$ may be unaccounted for mathematically because of the neglect of second order terms, in the expression for $K_{\text {conv }}$. The importance of the second order terms decreases as $\Delta t$ decreases, hence the isotherms should approach linearity as $\Delta t \rightarrow 0$.

There could be an appreciable error in interpolation of densities on the $32.054{ }^{\circ} \mathrm{C}$ isotherm of the $p V T$ measurements of Michels, Blaisse, and Michels. The values of density stated in table 2 are adjusted from the nominal values of $0.40,0.45,0.476,0.50$, and $0.55 \mathrm{~g} / \mathrm{cm}^{3}$ to give a smooth curve for a plot of $\Delta \rho / \Delta p$ versus $\bar{p}$. This is estimated to involve an error in $K$ of \pm 1 percent at $\rho=0.40$ and $0.55 \mathrm{~g} / \mathrm{cm}^{3}$, of \pm 2 percent at $\rho=0.45$ and $0.50 \mathrm{~g} / \mathrm{cm}^{3}$, and of \pm 3 percent at $\rho=0.476 \mathrm{~g} / \mathrm{cm}^{3}$.

The inset of figure 4, an isometric of $10^{5} \mathrm{~K}$ versus $t$ for $\rho=0.474 \mathrm{~g} / \mathrm{cm}^{3}$, suggests an extremely high value of $K$ at the critical point itself.

At high density, over a limited temperature range at least, the thermal conductivity of $\mathrm{CO}_{2}$ appears to be nearly constant at a given density. Thus $10^{5} \mathrm{~K}$ for $\mathrm{CO}_{2(l)}$ at $26.00{ }^{\circ} \mathrm{C}$ and $\rho=0.76 \mathrm{~g} / \mathrm{cm}^{3}$ is 20.4 and for $\mathrm{CO}_{2(g)}$ at $75.26{ }^{\circ} \mathrm{C}$ and $\rho=0.77$ is 20.8. For $\rho \geq 0.74 \mathrm{~g} / \mathrm{cm}^{3}$, all points of $K$ versus $\rho$ plot smoothly on a single curve regardless of temperature.

Any additional increment of thermal conductivity at the critical density has nearly vanished at $75^{\circ} \mathrm{C}$, and is $<25$ percent for $40^{\circ} \mathrm{C}$. The effect lies almost entirely between $\rho=0.30$ and $\rho=0.60 \mathrm{~g} / \mathrm{cm}^{3}$, which at $32.054^{\circ} \mathrm{C}$ is between $p=72.51$ and 75.90 atmospheres. Consequently, most investigations which "cover" the critical region in fact skip it, so that no unusual behavior is observed.

It is not unusual to assume that the density and temperature to which a measurement of the thermal conductivity corresponds is the average density and average temperature of the gas. Rigorously, the thermal conductivity should be defined as the limit of measurements at an average gas temperature and an average density, extrapolated to zero temperature difference. There will be no significant difference if $K$ may be satisfactorily represented as a linear function of $T$ and $\rho$, provided significant convection is absent. However, in the critical region, $K$ is not linearly, or even monotonically varying with $T$ and $\rho$, so that for reliability, $K$ should be extrapolated versus $\Delta t$ to zero temperature difference, even in the absence of convection.
The cell used in these measurements was designed to give high accuracy under conditions of low transport of heat by convection, a requirement in effect that the conductivity gap be large enough to minimize the error of the cell constant.

It would enhance the reliability of the results in the critical region if the conductivity gap were reduced to about one-third that used. Correspondingly, the ratio of $K$ conv/ $K$ gas would be reduced to one eighty-first of what was observed. However, the merit of the equipment used is manifested in the accuracy of the thermal conductivity at low and high densities.

\section{Comparison With Other Results}

Recently Sengers and Michels [13] have published a preliminary paper where measurements of the thermal conductivity of $\mathrm{CO}_{2}$ in the critical region are reported. The agreement between the results presented in this paper and the new work is satisfactory in the regions $0<\rho<0.20 \mathrm{~g} / \mathrm{cm}^{3}$ and $\rho \geq 0.65 \mathrm{~g} / \mathrm{cm}^{3}$ at all temperatures, and at all densities for $t \geq 40^{\circ} \mathrm{C}$. In the same units of $K$, Sengers and Michels show a value of $10^{5} \mathrm{~K}=21$ for $\rho=0.466 \mathrm{~g} / \mathrm{cm}^{3}$ and $t=34.8^{\circ} \mathrm{C}$, and a value of $10^{5} \mathrm{~K}=33$ for $\rho=0.466 \mathrm{~g} / \mathrm{cm}^{3}$ and $t=32.1{ }^{\circ} \mathrm{C}$. In addition, they have a $31.2{ }^{\circ} \mathrm{C}$ isotherm, with $10^{5} \mathrm{~K}=81$ at $\rho=0.466 \mathrm{~g} / \mathrm{cm}^{3}$. Therefore, the results of Sengers and Michels show a marked increase of the thermal conductivity of $\mathrm{CO}_{2}$ near the critical point, but less than that reported in this paper.

\section{Conclusions}

The thermal conductivity of carbon dioxide increases rapidly at the critical density as the critical temperature is approached from higher temperatures. Relatively large increases were observed only at temperatures less than $10{ }^{\circ} \mathrm{C}$ above the critical temperature, and over a density range between 0.30 to $0.60 \mathrm{~g} / \mathrm{cm}^{3}$. The corresponding pressure change is $3.4 \mathrm{~atm}$ at $32.054{ }^{\circ} \mathrm{C}$. Thus most prior measurements have not included much of the region where the phenomenon occurs.

The transport of heat by convection was very high for the measurements near the critical density at $32.054^{\circ} \mathrm{C}$. However, the limiting temperature difference for the transition to turbulent flow is high enough that extrapolation procedures should be valid.

It is estimated that the thermal conductivity values at low and high densities have high accuracy. At low densities, the values have the sort of temperature dependence that is regarded as typical of the thermal conductivities of dilute gases. However at densities above $\rho=0.74 \mathrm{~g} / \mathrm{cm}^{3}$, essentially no temperature dependence is manifested from 3.66 to $75.26^{\circ} \mathrm{C}$.

\section{References}

[1] S. Naldrett and O. Maass, Can. J. Research 18B, 322 (1940).

[2] IA. Michels, A. Botzen, and W. Schuurman, Physica 23, 95 (1957).

[3] W. Sellschopp, Forsch. Gebiete Ingenieurw, 5B, 162 (1934). 
[4] L. M. Lenoir and E. W. Comings, Chem. Eng. Prog. 47, 223 (1951).

[5] D. L. Timrot and V. G. Oskolkova, Izvestia V. T. I., No. 4 (1949).

[6] L. A. Guildner, J. Research NBS, 66A (Phys. and Chem.), No. 4, p. 333 (1962).

[7] S. C. Collins, Rev. Sci. Inst. 7, 502 (1936).

[8] A. W. Hull, Gen. Elec. Rev. 32, 390 (1929).

[9] O. C. Bridgeman, J. Am. Chem. Soc. 49, 1174 (1927).

10] A. Michels and C. Michels, Proc. Roy. Soc. (London) A153, 201 (1935).
[11] A. Michels, B. Blaisse, and C. Michels, Proc. Roy. Soc (London) A160, 358 (1937).

[12] R. Wentorf, Jr., J. Chem. Phys. 24, 607 (1956).

[13] J. V. Sengers and A. Michels, Prog. in Int. Res. on Thermodynamies and Transport Properties 434, ASME, Academic Press 1962, New York, N.Y. 